\title{
Protein overexpression and gene amplification of $H E R-2$ and EGFR in colorectal cancers: an immunohistochemical and fluorescent in situ hybridization study
}

\author{
Akishi Ooi ${ }^{1}$, Takuo Takehana ${ }^{1}$, Xiaoling Li $^{1}$, Shioto Suzuki ${ }^{1}$, Kazuyoshi Kunitomo ${ }^{1}$, \\ Hiroshi Iino ${ }^{2}$, Hideki Fujii ${ }^{2}$, Yasuhisa Takeda ${ }^{3}$ and Yoh Dobashi ${ }^{1}$ \\ ${ }^{1}$ Department of Pathology; ${ }^{2}$ Department of Surgery and ${ }^{3}$ Department of Health Sciences, School of Medicine, \\ University of Yamanashi, Yamanashi, Japan
}

\begin{abstract}
Overexpression of HER-2 and the epidermal growth factor receptor (EGFR) has been observed in many cancers, sometimes accompanied by gene amplification. To assess whether novel chemotherapies targeting these overexpressed proteins may be effective for the treatment of colorectal cancers, we examined the exact frequency of HER-2 and EGFR overexpression, the relationship between gene amplification and protein expression, and the heterogeneity of gene amplification within and between primary and metastatic tumors. We evaluated 244 colorectal cancers immunohistochemically. All tumors found to overexpress HER-2 or EGFR were further analyzed for gene amplification by fluorescent in situ DNA hybridization. Overexpression of HER-2 and EGFR was found in $8(3 \%)$ and $19(8 \%)$ of the 244 colorectal carcinomas, respectively. Gene amplification was observed in 100 and $58 \%$ of the tumors exhibiting HER-2 and EGFR overexpression, respectively. HER-2 amplification in cancer cells was characterized by clusters of hybridization signals, suggesting amplicons in homogeneously staining regions that were predominant in most primary and metastatic tumors. EGFR amplification, observed as scattered signals reminiscent of amplicons in double minute chromosomes, or coamplification of EGFR with the centromeric regions was observed as a minor population within primary tumors, and found in variety of populations in metastatic tumors. Overexpression of HER-2 and EGFR were observed in only a small fraction of colorectal carcinomas, but were frequently accompanied by gene amplification.

Modern Pathology (2004) 17, 895-904, advance online publication, 14 May 2004; doi:10.1038/modpathol.3800137
\end{abstract}

Keywords: HER-2; EGFR; FISH; colorectal cancer; immunohistochemistry; gene amplification

The HER-2 gene is located on chromosomal region $17 \mathrm{q} 11.2-\mathrm{q} 12$ and the EGFR gene is located on $7 \mathrm{p} 12$. These encode $185 \mathrm{kDa}$ (p185) and $170 \mathrm{kDa}$ plasma membrane glycoproteins, respectively. They share approximately $50 \%$ overall homology and are composed of an $\mathrm{N}$-terminus extracellular ligand-binding domain, a transmembrane lipophilic segment, and a C-terminus intracellular region containing a tyrosine kinase domain. ${ }^{1}$ High-affinity ligand binding causes receptor dimerization, which results in the activation of an intrinsic protein

Correspondence: A Ooi, MD, Department of Pathology, Faculty of Medicine University of Yamanashi, 1110 Shimokato, Tamahocho, Nakakoma-gun, Yamanashi 409-3898, Japan.

E-mail: aooi@res.yamanashi-med.ac.jp

Received 22 January 2004; revised 9 March 2004; accepted 11

March 2004; published online 14 May 2004 tyrosine kinase activity and tyrosine autophosphorylation. These events activate a cascade of biochemical and physiological responses that are relayed to transcription factors, resulting in changes in gene and protein expression. Thus, these proteins are categorized as type I receptor tyrosine kinases (RTK).

Recently, these type I RTKs have attracted great deal of attention, due to the development of several clinical therapies targeting them. Antibodies against the external domains of these receptors, or small molecule inhibitors targeting their kinase activities are in development and/or approved for therapy and have garnered much attention for their dramatic effectiveness in some patients. The humanized monoclonal antibody against the external domain of HER-2 (trastuzumab or Herceptin ${ }^{\mathrm{TM}}$, Genentech Inc., South San Francisco, CA, USA) is the most 
successful example. This monoclonal antibodybased therapy has been approved for use in breast cancer patients and has demonstrated an ability to extend median survival time in metastatic breast cancer patients exhibiting HER-2 overexpression. ${ }^{2}$ Similarly, IMC-C225 (cetuximab or Erbitux ${ }^{\mathrm{TM}}$, ImClone Systems Inc., Branchburg, NJ, USA), a monoclonal antibody targeting EGFR, and among the various small molecule inhibitors of tyrosine kinases ZD1839 (gefitinib, Iressa ${ }^{\mathrm{TM}}$, AstraZeneca, Macclesfield, UK) are now approved for use in patients with colorectal cancers (FDA News, February 12, 2004) and non-small cell lung cancer, ${ }^{3}$ respectively.

It has been established that in breast cancer, HER2 overexpression is principally the result of gene amplification. The US Food and Drug Administration approves the use of trastuzumab therapy in cases where HER-2 overexpression is detected by immunohistochemistry (IHC) or gene amplification is detected by fluorescent in situ hybridization (FISH). In addition to breast, lung, and colorectal carcinomas, many types of epithelial malignancies reportedly display increased HER-2 and/or EGFR expression on their surface membranes, sometimes accompanied by gene amplification. We have examined the expression of HER-2 in gastric ${ }^{4-6}$ and lung cancers, ${ }^{7}$ and of EGFR in gastric cancers ${ }^{8}$ using IHC, as well as gene amplification using FISH. We have shown that the major mechanism of protein overexpression in these cancers is gene amplification. In particular, in gastric and lung carcinomas, most tumor cells exhibiting HER-2 amplification exhibited signals localized to one or two clusters, indicating that the amplified gene was present in homogeneously staining regions (HSRs), similar to those observed in breast cancers. Thus, we have proposed that trastuzumab should be considered when designing adjuvant therapy for patients with gastric and lung cancers. ${ }^{4-7}$

Colorectal carcinoma is the second leading cause of cancer death in the Western world. There have been many studies examining the overexpression HER-2 and EGFR in colorectal cancers; however, there are numerous discrepancies in the frequencies reported from IHC studies. There have been few studies examining gene amplification of HER-2 and EGFR in colorectal carcinomas. This encouraged us to examine colorectal cancer for aberrations in HER-2 and EGFR expression and gene copy number using combined IHC and FISH techniques. Our aim was to provide some rationale for the introduction of new adjuvant therapies for colorectal cancer patients. We sought first to determine the exact frequencies of HER-2 and EGFR abnormalities in colorectal cancers; second, to clarify the relationship between protein overexpression and gene amplification of HER-2 and EGFR and; third, to examine possible genetic heterogeneity of HER-2 and EGFR within and between primary and metastatic tumors.

\section{Materials and methods}

\section{Tissue Samples}

We examined 244 primary colorectal carcinomas and concurrently excised nodal metastases obtained from consecutive surgeries performed at the Department of Surgery, Yamanashi Medical University between 1994 and 2002. The patients consisted of 150 men and 94 women with a median age of 65.0 years (mean, 64.7; range, 32-91). The condition of the patients was assessed according to the system for staging primary tumor/regional lymph nodes/distant metastasis (TNM) described in the AJCC Cancer Staging Manual. ${ }^{9}$ The World Health Organization Classification of Tumors ${ }^{10}$ was used to determine histological classification. The 244 patients were classified into the TNM stages as follows: Stage 0, 8 patients; Stage I, 47 patients; Stage II, 76 patients; Stage III, 85 patients; and Stage IV, 28 patients. Histologically, the specimens were divided into 102 well-differentiated, 120 moderately differentiated, five poorly differentiated adenocarcinomas, and 16 mucinous carcinomas and one signet-ring cell carcinoma. This laboratory study was approved by the Institutional Review Board at the University of Yamanashi, and written informed consent was obtained from all patients.

\section{IHC}

Resected colon samples were immediately immersed in $20 \%$ buffered neutral formalin, fixed overnight, and embedded in paraffin according to standard procedures. Since immunoreactivity diminishes with time in formalin-fixed, paraffinembedded sections stored on glass slides at room temperature, all sections $(4 \mu \mathrm{m})$ were stained within 6 weeks of being cut. Serial sections $(4 \mu \mathrm{m})$ that had been cut from representative formalinfixed, paraffin-embedded cancer tissues and placed onto silanated glass slides (Matsunami, Tokyo, Japan) were used for hematoxylin-eosin staining, IHC detection of the HER-2 and EGFR, and FISH analysis. IHC detection of HER-2 and EGFR were carried out on all the primary tumors, as well as metastatic tumors of the lymph nodes in those cases where protein overexpression was detected in the primary tumors. A polyclonal antibody (Nichirei, Tokyo, Japan; dilution, 1:100) against the internal domain of the human HER-2, and a monoclonal antibody against the external domain of human EGFR (Novocastra Lab, Newcastle, UK; Working dilution, 1:20) were used. The specificities and sensitivities of the antibodies against HER-2 and EGFR were verified previously. ${ }^{4-7,11,12}$ For EGFR detection, a high-temperature antigen unmasking technique was used: that is, autoclave the section in $0.01 \mathrm{M}$ citrate buffer (pH 7.0) at $121^{\circ} \mathrm{C}$ for $10 \mathrm{~min}$. Antibodies were visualized by avidin-biotin binding to peroxidase-conjugated 
secondary antibodies. In each analysis, a gastric cancer section that had been previously confirmed to overexpress HER-2 or EGFR ${ }^{5,8}$ was included as a positive control.

HER-2 and EGFR positivity in the IHC analyses were reviewed by three pathologists (TT, SS, AO), who were unaware of the gene amplification. The intensity of reactivity was scored using a four-tier system: negative, no discernible staining or background type staining: $1+$, definite cytoplasmic staining and/or equivocal discontinuous membrane staining: $2+$, unequivocal membrane staining with moderate intensity: $3+$ strong and complete plasma membrane staining. Samples exhibiting $2+$ or $3+$ immunostaining were considered positive. For both HER-2 and EGFR, the extent (\%) of positive staining cells was measured in the representative large section in each tumor.

\section{FISH}

FISH analysis was undertaken for all $2+$ and $3+$ staining primary tumors and their metastatic lymph nodes and for $341+$ staining samples. In addition, 30 tumors scoring negative for EGFR, and 30 tumors scoring negative for HER-2 were selected at random. Gene amplification of HER-2 (chromosomal locus 17q11.2-q12) and EGFR (7p12) were determined using fluorescently labeled DNA probe sets purchased from Vysis, Inc. (Downers Grove, IL, USA): LSI HER-2/CEP $17^{\text {TM }}$ for HER-2 and LSI EGFR/ CEP $7^{\mathrm{TM}}$ for EGFR. When necessary, LSI D7S486/CEP $7^{\mathrm{TM}}$ (Vysis) was also used to examine gene amplification of 7q31. Each probe sets contains a SpectrumOrange ${ }^{\mathrm{TM}}$-labeled gene (locus)-specific probe and a SpectrumGreen ${ }^{\mathrm{TM}}$-labeled centromeric probe hybridized to centromeric region of the chromosome as the control to normalize copy number for each chromosome.

FISH was performed using standard methods, with a modification to incorporate an intermittent, short-term microwave treatment during the initial period of hybridization. ${ }^{13}$ In brief, $4 \mu \mathrm{m}$ sections were deparaffinized by five successive, 3-min washes in xylene followed by five washes in ethanol and heating in a $0.01 \mathrm{M}$ citrate buffer $(\mathrm{pH}$ 6.0) using a microwave processor (MI-77, Azumaya Company, Tokyo, Japan) for $10 \mathrm{~min}$. After treatment in $0.2 \%$ pepsin $/ 0.01 \mathrm{~N} \mathrm{HCl}$ for $10 \mathrm{~min}$ at $37^{\circ} \mathrm{C}$, the samples were aged in $0.1 \% \mathrm{NP}-40 / 2 \times \mathrm{SSC}$ for $10 \mathrm{~min}$ at $37^{\circ} \mathrm{C}$ and their DNA was denatured by treatment in $70 \%$ formamide $/ 2 \times$ SSC for $5 \mathrm{~min}$ at $85^{\circ} \mathrm{C}$. A measure of $10 \mu \mathrm{l}$ of the probe solution was then placed on a glass slide with a coverslip. The sample slides in the hybridization mixture were then put in a microwave processor and were irradiated for $3 \mathrm{~s}$ at $2 \mathrm{~s}$ intervals $(2.45 \mathrm{GHz}, 300 \mathrm{~W})$ with the temperature sensor set at $42^{\circ} \mathrm{C}$, and then hybridized at $42^{\circ} \mathrm{C}$ overnight. Posthybridization washing was carried out according to the manufacturer's protocol. The tissue sections were counterstained with $4^{\prime}, 6$-diamidine-2' indole dihydrochloride and $p$-phenylenediamine in phosphate-buffered saline and glycerol (DAPI II) (Vysis) and examined with a fluorescence microscope (Olympus, Tokyo, Japan) equipped with the Triple Bandpass Filter set (Vysis) for DAPI II, SpectrumOrange and SpectrumGreen, and filter sets specific to SpectrumOrange and SpectrumGreen. As positive controls, gastric cancer tissues that had been previously confirmed to have amplification of HER-2 or EGFR were used..$^{5,8}$

A cell was scored as positive for amplification when a definite cluster or more than 10 orange signals were found, as described previously. ${ }^{4,5,8}$ FISH images were taken using a photographic camera and recorded on film slides.

\section{Statistical Analysis}

Agreement among observers in interpretation of IHC specimens, and the associations between protein overexpression and amplification of EGFR or HER-2 were tested by kappa $(\kappa)$ statistics. ${ }^{14}$ In accordance with the criteria of Landis and Koch, ${ }^{15}$ the $\kappa$-values were divided into several scales to evaluate the strength of the agreement: $\kappa<0.00$, poor; $0.00<$ $\kappa<0.20$, slight; $0.21<\kappa<0.40$, fair; $0.41<\kappa<0.60$, moderate; $0.61<\kappa<0.80$, substantial; and $0.81<\kappa$ $<1.00$, nearly perfect. A $\chi^{2}$-test for independence was used to examine the correlation between overexpression of HER-2 and EGFR, and between overexpression of HER-2 or EGFR and the several histological classifications. Spearman's correlation coefficient by rank was used to analyze the association of expression of HER-2 or EGFR with the various pathological stages.

\section{Results}

\section{IHC}

Clinicopathological data and immunostaining results for the 27 cases exhibiting overexpression of HER-2 or EGFR are summarized in Table 1. Overexpression of HER-2 was found in eight $(3 \%)$ of the 244 colorectal carcinomas analyzed (Figure 1a). The remaining 236 cases were all negative, with no tumors staining $1+$ or higher. Overall interobserver agreement was substantial $(\kappa=0.64,95 \%$ confidence interval (CI), 0.58-0.69), and in particular agreement for the $3+$ staining cases was nearly perfect $(\kappa=0.89,95 \%$ CI, 0.81-0.96). Overexpression of EGFR was found in $19(8 \%)$ of the 244 tumors, and $1+$ staining was found in 105 of the tumors. Although interobserver agreement was substantial $(\kappa=0.80 ; 95 \%$ CI, 0.72-0.87) and moderate $(\kappa=0.50 ; 95 \%$ CI, $0.42-0.57)$ for $1+$ and $2+$ staining respectively, it was nearly perfect for 
Table 1 Pathological classification and result of IHC and Fish analysis of HER-2(a) and EGFR(b)

\begin{tabular}{|c|c|c|c|c|c|c|c|c|c|c|c|c|}
\hline \multirow{2}{*}{$\begin{array}{l}\text { Case } \\
\text { no. }\end{array}$} & \multirow{2}{*}{$\begin{array}{c}\text { Age } \\
\text { (years) }\end{array}$} & \multirow[t]{2}{*}{ Sex } & \multirow[t]{2}{*}{ Site } & \multirow[t]{2}{*}{$p T$} & \multirow[t]{2}{*}{$p N$} & \multirow[t]{2}{*}{ Metastasis } & \multirow[t]{2}{*}{ Stage } & \multirow{2}{*}{$\begin{array}{c}\text { Histological } \\
\text { classification }\end{array}$} & \multicolumn{2}{|c|}{ Primary tumor } & \multicolumn{2}{|c|}{ Lymph node metastasis } \\
\hline & & & & & & & & & $\begin{array}{c}\text { IHC \% of } \\
\text { positive } \\
\text { cells }\end{array}$ & $\begin{array}{c}\text { FISH Type } \\
\text { of } \\
\text { amplification }\end{array}$ & $\begin{array}{c}\text { No. of positive } \\
\text { nodes/No. of } \\
\text { metastatic } \\
\text { nodes }\end{array}$ & $\begin{array}{c}\text { FISH } \\
\text { Type of } \\
\text { amplification }\end{array}$ \\
\hline
\end{tabular}

\begin{tabular}{llllll}
\hline \multicolumn{2}{l}{ (a) HER-2 } & & & & \\
1 & 72 & $\mathrm{M}$ & $\mathrm{A}$ & 3 & 2 \\
2 & 83 & $\mathrm{~F}$ & $\mathrm{R}$ & 4 & 0 \\
3 & 75 & $\mathrm{~F}$ & $\mathrm{~S}$ & 3 & 1 \\
4 & 53 & $\mathrm{~F}$ & $\mathrm{R}$ & 3 & 2 \\
5 & 59 & $\mathrm{M}$ & $\mathrm{S}$ & 3 & 1 \\
6 & 71 & $\mathrm{M}$ & $\mathrm{R}$ & 2 & 0 \\
7 & 57 & $\mathrm{~F}$ & $\mathrm{~T}$ & 3 & 1 \\
8 & 67 & $\mathrm{~F}$ & $\mathrm{R}$ & 1 & 0
\end{tabular}

1 (liver)
1 (liver)
0
0
0
0
0
0

$\begin{array}{ccl}\text { IV } & \text { wel } & 3+,>90 \\ \text { IV } & \text { mod } & 3+, 80-90 \\ \text { III } & \text { mod } & 3+,>90 \\ \text { III } & \text { wel } & 3+,>90 \\ \text { III } & \text { wel } & 3+,>90 \\ \text { I } & \text { wel } & 3+,>90 \\ \text { III } & \text { wel } & 2+, 80-90 \\ \text { I } & \text { mod } & 2+, 30-40\end{array}$

$\mathrm{CL}$
$\mathrm{CL}$
$\mathrm{CL}$
$\mathrm{CL}$
$\mathrm{CL} / \mathrm{SC}$
$\mathrm{CL}$
$\mathrm{CL}$
$\mathrm{CL}$

$\begin{array}{cl}\text { mod } & 3+,<5 \\ \text { mod } & 3+, 50-60 \\ \text { por } & 3+, 40-50 \\ \text { wel } & 3+, 30-40 \\ \text { mod } & 3+,<5 \\ \text { mod } & 3+,<5 \\ \text { wel } & 3+, 10-20 \\ \text { mod } & 3+,<5 \\ \text { wel } & 3+,<5 \\ \text { wel } & 3+, \text { SSCB, }<5 \\ \text { mod } & 2+, 10-20 \\ \text { muc } & 2+, 10-20 \\ \text { mod } & 2+, \text { SSCB, }<1 \\ \text { mod } & 2+, 10-20 \\ \text { mod } & 2+,<5 \\ \text { wel } & 2+, \text { SSCB },<5 \\ \text { wel } & 2+, \text { SSCB }<5 \\ \text { mod } & 2+, \text { SSCB, }<5 \\ \text { wel } & 2+, \text { SSCB }<5\end{array}$

SC/CL
SC
SC
SC
SC
SC
SC
SC
SC
$(-)$
CA
$(-)$
$(-)$
CA/CL
$(-)$
$(-)$
$(-)$
$(-)$
$(-)$

$4 / 4$
$(-)$
$1 / 1$
$5 / 5$
$2 / 2$
$(-)$
$1 / 1$
$(-)$

CL
CLa
CL
CL
SC
CL

\begin{tabular}{|c|c|c|c|c|}
\hline \multicolumn{5}{|c|}{ (b) EGFR } \\
\hline 9 & 64 & $\mathrm{M}$ & $\mathrm{R}$ & 3 \\
\hline 10 & 82 & $\mathrm{M}$ & S & 4 \\
\hline 11 & 69 & $\mathrm{M}$ & $\mathrm{R}$ & 4 \\
\hline 12 & 63 & $\mathrm{M}$ & $S$ & 3 \\
\hline 13 & 69 & $\mathrm{M}$ & A & 3 \\
\hline 14 & 77 & $\mathrm{M}$ & $S$ & 4 \\
\hline 15 & 39 & $\mathrm{M}$ & $\mathrm{R}$ & 3 \\
\hline 16 & 81 & $\mathrm{M}$ & $\mathrm{R}$ & 3 \\
\hline 17 & 61 & $\mathrm{M}$ & $S$ & 3 \\
\hline 18 & 58 & $\mathrm{~F}$ & A & 4 \\
\hline 19 & 61 & $\mathrm{M}$ & $S$ & 4 \\
\hline 20 & 69 & $\mathrm{M}$ & $\mathrm{R}$ & 3 \\
\hline 21 & 44 & $\mathrm{M}$ & $\mathrm{R}$ & 3 \\
\hline 22 & 80 & $\mathrm{~F}$ & $\mathrm{R}$ & 3 \\
\hline 23 & 70 & $\mathrm{M}$ & $\mathrm{T}$ & 1 \\
\hline 24 & 65 & $\mathrm{M}$ & $\mathrm{R}$ & 3 \\
\hline 25 & 75 & $\mathrm{~F}$ & $\mathrm{D}$ & 3 \\
\hline 26 & 71 & $\mathrm{M}$ & $\mathrm{T}$ & 2 \\
\hline 27 & 67 & $\mathrm{M}$ & $\mathrm{R}$ & 1 \\
\hline
\end{tabular}

$\begin{array}{cc}1 \text { (Ap/Gb) } & \text { IV } \\ 0 & \text { III } \\ 0 & \text { III } \\ 0 & \text { III } \\ 0 & \text { III } \\ 0 & \text { III } \\ 0 & \text { II } \\ 0 & \text { II } \\ 0 & \text { II } \\ 0 & \text { II } \\ 0 \text { (Om) } & \text { IV } \\ 1(\text { lung) } & \text { IV } \\ 1 \text { (liver/Gb) } & \text { IV } \\ 0 & \text { III } \\ 0 & \text { III } \\ 0 & \text { III } \\ 0 & \text { II } \\ 0 & \text { I } \\ 0 & \text { I }\end{array}$

$\begin{array}{cc}\text { IV } & \text { mod } \\ \text { III } & \text { mod } \\ \text { III } & \text { por } \\ \text { III } & \text { wel } \\ \text { III } & \text { mod } \\ \text { III } & \text { mod } \\ \text { II } & \text { wel } \\ \text { II } & \text { mod } \\ \text { II } & \text { wel } \\ \text { II } & \text { wel } \\ \text { IV } & \text { mod } \\ \text { IV } & \text { muc } \\ \text { IV } & \text { mod } \\ \text { III } & \text { mod } \\ \text { III } & \text { mod } \\ \text { III } & \text { wel } \\ \text { II } & \text { wel } \\ \text { I } & \text { mod } \\ \text { I } & \text { wel }\end{array}$

Abbreviations: M, male; F, female; A, ascending colon; R, rectum; S, sigmoid colon; T, transverse colon; D, descending colon; wel, well differentiated; mod, moderately differentiated; por, poorly differentiated; SSCB, small scattered clusters and buds; CL, cluster type; SC, scattered type; CA, coamplified type; AP, appendix; Gb, gallbladder; Om, omentum.

${ }^{\mathrm{a}}$ Liver metastasis.

negative $(\kappa=0.86 ; \quad 95 \% \quad \mathrm{CI}, \quad 0.79-0.94)$ and $3+$ staining $(\kappa=0.93 ; 95 \%$ CI, $0.85-1.00)$.

In tumors exhibiting HER-2 overexpression, more than $80 \%$ of the cells in the specimens were positive for HER-2 staining, with the sole exception of Case 8 , in which only $30-40 \%$ of cells showed positive staining. In contrast, in tumors exhibiting EGFR overexpression, high EGFR-expressing cells were localized into separate zones or foci (Figure 1b), and in all cases, except Case 10, positive cells comprised no more than $50 \%$ of the total cells. In 12 of the cases, positive cells comprised less than $5 \%$ of the total. In six of the 10 tumors containing $2+$ staining cancer cells, positive staining was confined to small solid clusters or buds (SSCB) that emerge from the base or lateral edge of malignant glands (Figure 1c). In Case 11, overexpression was found predominantly in poorly differentiated cells (Figure 1d). In the rest of the tumors, no morphological distinction between positive and negative cancer cells were observed. There was no significant correlation between protein overexpression and histo- logical type. We did not encounter a case in which both HER-2 and EGFR were concomitantly overexpressed. Statistically, no correlation was found between overexpression of these two oncoproteins.

\section{FISH}

By FISH analysis, all HER-2-overexpressing tumors also exhibited HER-2 amplification. HER-2 amplification was not found in any of the 30 negative controls. Thus, overexpression and amplification of HER-2 completely coincided. With regard to EGFR, nine of the $103+$ staining tumors and two of the nine $2+$ staining tumors were found to contain cancer cells exhibiting EGFR amplification. However, no gene amplification was found among any of the immunostained SSCB samples. Also, no gene amplification was observed among the 34 tumors exhibiting $1+$ staining or the 30 nonimmunostaining control tumors. The association between protein 

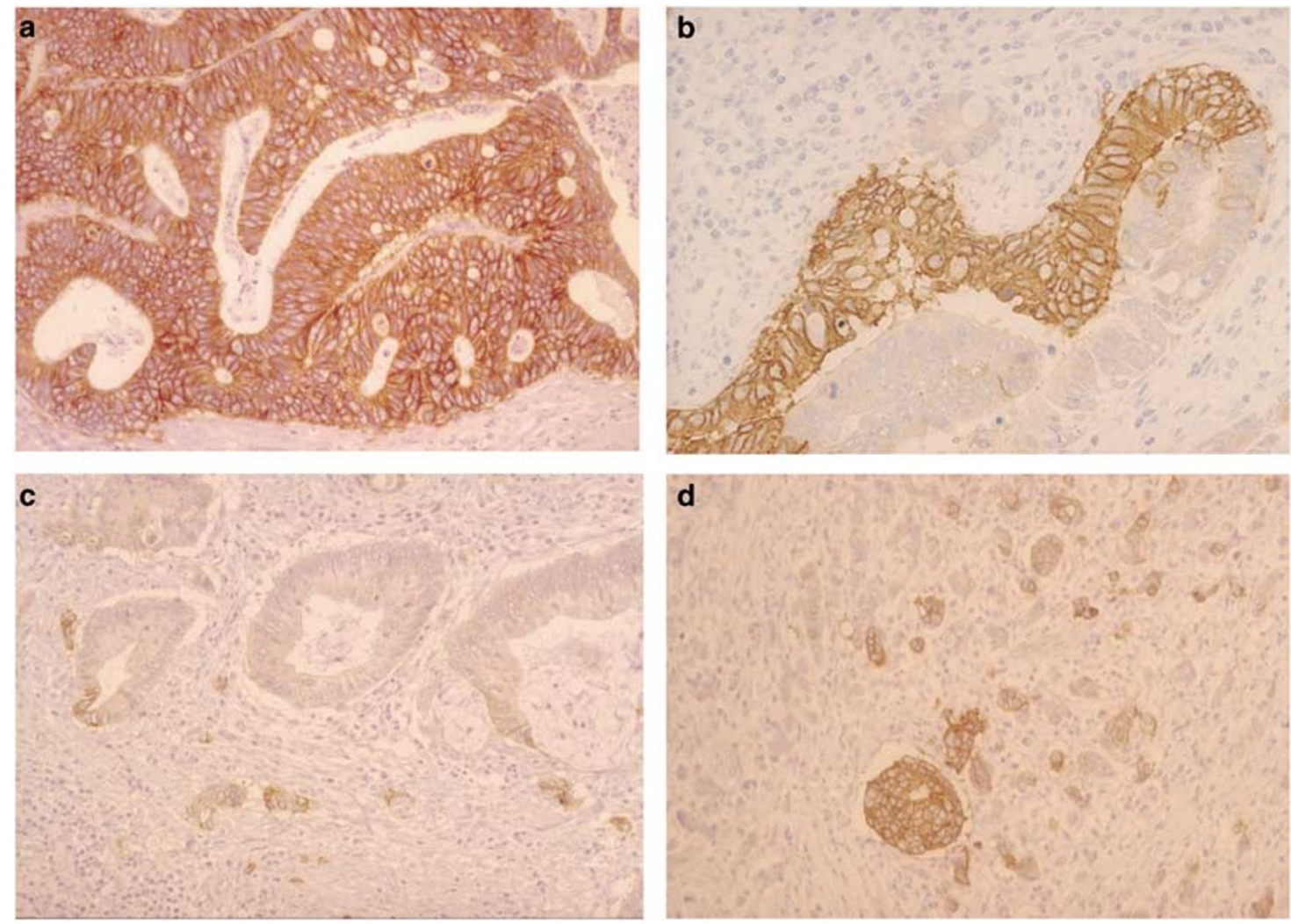

Figure 1 IHC of cells overexpressing HER-2 (a) and EGFR (b, c, and d). (a) Plasma membrane of adenocarcinoma cells exhibiting $3+$ staining (Case 1; × 125); (b) single cancer tubule composed of EGFR-positive and -negative cells (Case 15; $\times 250$ ); (c) EGFR staining was confined to SSCB that emerge from the base or lateral edge of malignant glands (Case 18; $\times 125$ ); (d) Poorly differentiated adenocarcinoma composed of EGFR-positive and negative cells (Case 11; × 125).

overexpression and amplification of EGFR was substantial $(\kappa=0.65 ; 95 \%$ CI, 0.48-0.88).

By FISH analysis, three major different amplification patterns were observed: one type consisted of one or two distinct clusters of orange signals ('cluster type'; Figure 2a), and the second type as more than 10 scattered orange signals ('scattered type'; Figure 2b). In both of these first two types, fewer than five green signals were observed. In the third type, more than 10 loosely clustered orange signals were found, accompanied with a similar number of green signals ('accompanied type'; Figure 2c, d). HER-2 amplification was of the cluster type (first type) in all the positive tumors, although cluster-type appeared together with scattered-type in Case 5 (Figure 2e). Amplification of the $E G F R$ was found to be of the scattered-type in nine tumors, although scattered-type was combined with cluster-type presentation in Case 9. Accompaniedtype was observed in Cases 19 and 22. In both tumors, FISH analysis was repeated using the LSI D7S486/CEP $7^{\mathrm{TM}}$ probe, which revealed a copy number of 1-4 for $7 \mathrm{q} 31$ with no specific gene amplification (Figure 2f).

When tissue sections used for FISH were compared with serial sections used for immunostaining, the regions of cancer cells displaying gene amplifi- cation and protein overexpression completely overlapped, for both HER-2- and EGFR-positive tumors. Namely, HER-2 amplification was found more than $80 \%$ of the cells, being contras with EGFR amplification which was less than $50 \%$ in most tumors. This colocalization could sometimes be confirmed on a cell-by-cell basis, as shown in Figures $1 \mathrm{~b}$ and $2 b$.

Six of the eight cases exhibiting HER-2 overexpression in the primary tumors had lymph node metastases and/or liver metastasis. All the metastatic nodes (13) and the liver metastasis (one) examined contained predominantly HER-2 overexpressing cells, with accompanying gene amplification. Among the 19 cases exhibiting overexpression of EGFR in the primary tumors, 12 had lymph nodes metastases and only three had EGFR-overexpressing cancer cells in the metastatic nodes, including Case 19 , in which half of the metastatic nodes scored negative for overexpression. FISH analysis of EGFRoverexpressing tumors in lymph nodes revealed a mosaic pattern of amplified and nonamplified cells in Cases 11, 12, and 19 (Figure 2g). The types of amplification in the primary and metastatic tumors were the same, except in Case 5, where metastatic tumors lacked a cluster-type FISH pattern, and in Case 19, in which both accompanied-type and 
scattered-type patterns were observed in separate metastatic foci. Overexpression of HER-2 was not correlated with pathological stage. There was also no correlation between overall overexpression of
EGFR and pathological stage; however, there was a positive correlation when only 11 overexpressing cases exhibiting gene amplification were included $(P<0.05)$.
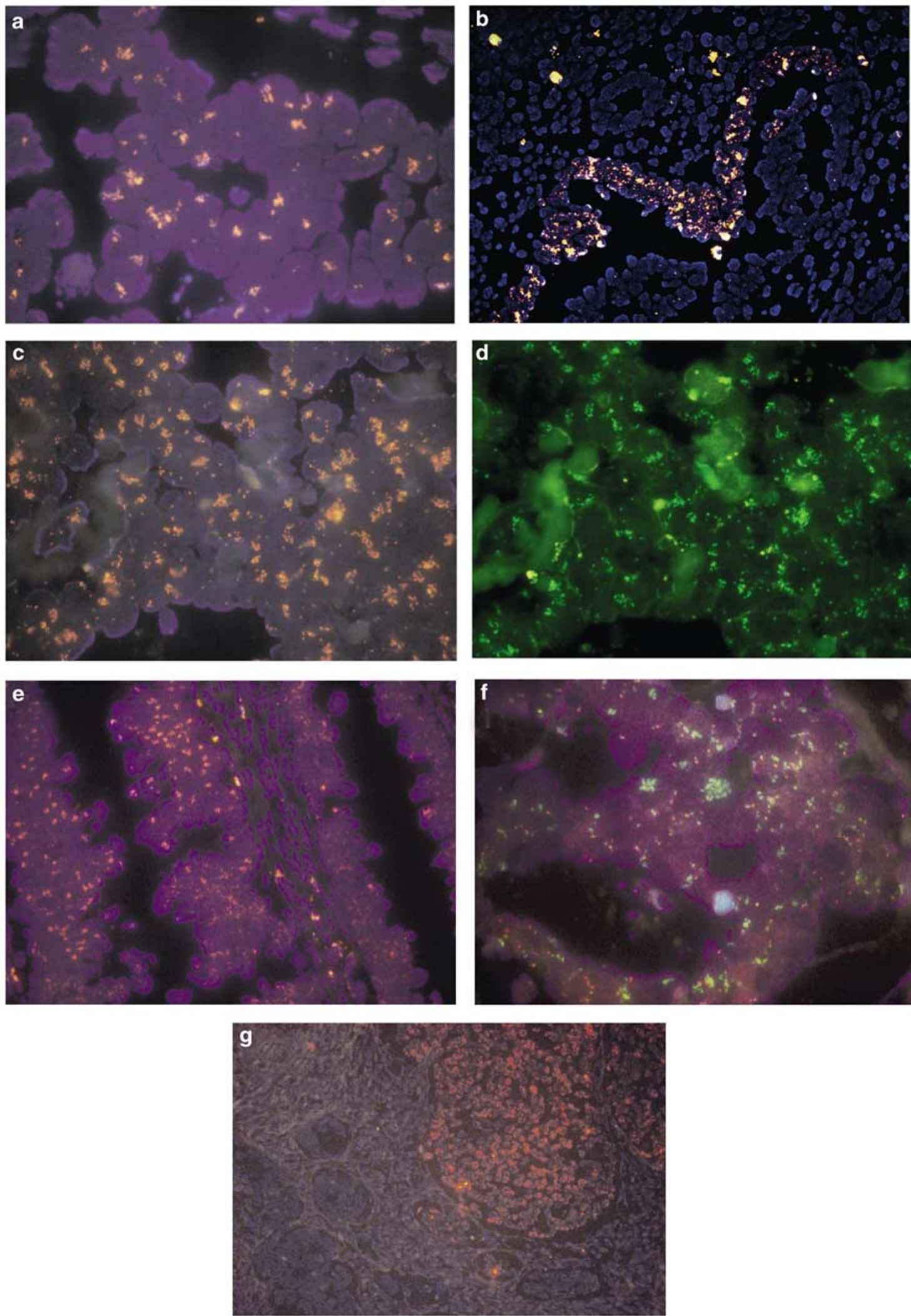


\section{Discussion}

Overexpression of HER-2 was found in 3\% (eight of 244) of colorectal cancers, and in all of these, amplification of the HER-2 was observed. Overexpression of EGFR was found in 19 of the $244(8 \%)$ cases of colorectal cancer, and gene amplification was observed in 11 of these. In previous IHC studies, there was considerable discrepancy in the frequencies and distribution of HER-2 and EGFR overexpression in colorectal carcinomas, as described below. These discrepancies were probably due to differences in tissue-fixation methods, the antibodies used, and the detection techniques and criteria for evaluating the results. Previous IHC studies examining HER-2 expression reported different percentages of positive cells, ranging from 0 to $100 \% .{ }^{16-24}$ The major cause of these discrepancies seems to be the different criteria for evaluating the results. Studies that scored intracytoplasmic staining as positive reported larger frequencies, whereas studies that reported only membrane staining as positive was scored lower or zero frequency. ${ }^{16-19,22-24}$ The results of the current study appear similar to those of Osako et $a l,{ }^{22}$ who used the same antibody as in our study. They observed membranous staining in only $3 \%$ of colorectal carcinomas (three of 100), and demonstrated gene amplification by Southern blot analysis in one of the three. ${ }^{22}$ The results of a recent study by McKay et $a l^{23}$ also seemed similar to ours; only eight out of 248 (3\%) displayed strong immunoreactivity in the membrane of tumor cells, although $82 \%$ of the tumors expressed equivalent levels in adjacent normal mucosa. Most recently, Nathanson et $a{ }^{16}$ reported an incidence of $4 \%$ (five of 139) HER-2 overexpression by IHC, which showed extreme high concordance $(\kappa=0.85)$ with gene amplification detected by FISH.

In contrast, Kapitanovic et $a 2^{24}$ observed HER-2 immunoreactivity in normal colon tissue, especially adjacent to carcinoma, hyperplastic polyps, adenomas, and adenocarcinomas at different frequencies, intensities and extents in each case, and overall positivity in adenocarcinomas was $100 \%$. Cytoplasmic and membrane staining seen with IHC was verified by the fact that p185 (HER-2) and phosphotyrosine were detected by Western blot analysis in both the membrane and cytosolic fractions. At the present time, the significance of cytosolic p185 is unclear, and in our own study no significant cytoplasmic staining was observed. Our study showed that overexpression of HER-2 in the cellular membrane in colorectal carcinomas is probably the result of HER-2 amplification, mostly occurring in cell clusters. This mechanism of increased HER-2 expression is similar to that known to occur in breast cancers. ${ }^{25}$

There also have been discrepancies in the reported frequencies of cells positive for EGFR and their distribution in previous IHC studies. The reason seems to be that antibodies that reliably detect EGFR expression in fixed and paraffinembedded pathological material have only recently become available ${ }^{26}$ as well as differences in scoring as described for HER-2 above. ${ }^{27}$ Recently, Goldstein and Armin $^{28}$ noted that exclusive membrane immunoreactivity usually occurred in two morphological patterns. One was in undifferentiated cells, which were comprised of discontinuous, isolated single or small clusters of malignant cells in the stroma. The second was in SSCB that emerged from the base or lateral edge of malignant glands and that frequently were angulated. They speculated that tumor cells in the former type progress into those in the latter type. ${ }^{28}$ In our present study, we found six tumors with SSCB overexpressing EGFR, and also single tumor (Case 11) with a predominant component of undifferentiated desmoplastic carcinoma overexpressing EGFR. This tumor was associated with EGFR gene amplification; however, the six tumors with SSCB had no gene amplification, thus we found no genetic evidence to link the two types of EGFR-overexpressing tumors. The mechanism by which EGFR is overexpressed in the SSCB is unknown at the present time.

Excluding the five tumors with SSCB and the other two $2+$ staining tumors, all the tumors exhibiting overexpression had amplification of the EGFR gene, mostly of the scattered-type. Furthermore, when IHC and FISH were compared in adjacent sections in these tumors, the coincidence of gene amplification and overexpression was confirmed almost on a cell-by-cell basis. The monoclonal antibody used is specific to the extracellular domain of EGFR. Expression of highly oncogenic variant III of EGFR, which is absent of the extracellular domain, may not be detected with this antibody. ${ }^{29}$ The DNA probe for EGFR spans the entire gene would likely detect any amplification, even the mutated form of the receptor. However, because the FISH analysis could not detect any amplified cells in 64 tumors without EGFR over-

Figure 2 Dual-color FISH analysis of HER-2/centromere 17 (a and e), EGFR/centromere 7 (b, c, and g) and $7 q 31 /$ centromere 7 (f). (a) One or two clusters of orange signals of HER-2 are found in cancer nuclei (Case $1 ; \times 625$ ). (b) Same field of Figure 1 b. FISH on a serial section shows $3+$ staining cancer cells have multiple scattered orange signals of the EGFR gene $($ Case 15 ; $\times 250)$. (c and d) The same field was observed by the triple band filter (c) and the SpectrumGreen ${ }^{\mathrm{TM}}$-specific filter (d). Coamplified EGFR and centromere 7 are found to form loose clusters in the cancer nuclei (Case 19; $\times 625)$. (e) Cancer tubules are composed of cells with clustered signals and scattered signals of HER-2 (Case 5; × 250). (f) Cancer nuclei exhibited amplification of centromere 7 region (green signals), but no amplification of $7 q 31$ (orange signals) (Case 19; ×625). (g) Amplification-positive and -negative cells were found in a metastatic lymph node (g) (Case 11; $\times 125)$. 
expression, it is very unlikely that variant III of EGFR is overexpressed by gene amplification in colorectal cancers. In most colorectal cancers, overexpression of EGFR caused by gene amplification comprised only a small portion of the cells in these tumors. Previous Southern blot studies as well as a study using quantitative real-time polymerase chain reaction have been unable to demonstrate EGFR gene amplification in colorectal cancers. ${ }^{30,31}$ This could be explained by sampling errors or dilution on any positive signals when extracts from entire populations of cells are analyzed.

In mammalian cells, highly amplified DNA is found within two distinct structures: homogeneously staining regions (HSRs), which are located within a chromosomal site in the form of expanded chromosomal regions, and double minute chromosomes (DM), which are centromere-free circular structures. $^{32}$ It is generally accepted that clustered signals found by FISH correspond to amplified signals in HSR, and scattered signals correspond to DM, excluding a few exceptional cases. In the present study, amplification of HER-2 was detected as clustered signals, and that of EGFR was detected as scattered signals in most cancer cells. Thus, it appears that the principal amplification pattern of HER-2 is HSR, and that of EGFR is DM. More direct evidence of amplified EGFR genes occurring in DMs of colon cancer cells was provided by Dolf et $a l^{33}$ who used in situ hybridization of metaphase spreads in the colon cancer cell line DiFi, which had been established from the colon cancer of a patient with Gardner syndrome. It has been shown that in several cell lines amplified genes in the DM chromosomes were integrated into HSRs, whereas the converse breakdown of HSR to generate DM chromosomes has not been observed. ${ }^{34}$ In Cases 5 and 9, HSR and DM were found to coexist. This could represent the integration of DM to HSR in vivo. However, according to Dolf et al, no signs of stable reintegration of amplified EGFR have been observed in DiFi cells over the course of 3 years of cell culture. ${ }^{33}$

We are not aware of any previous reports of coamplification-type gene amplification. Usually, a centromeric probe is used as a reference probe to assist in distinguishing gene amplification from chromosomal polysomy in dual-color FISH. Increased gene number accompanied by an increase in the copy number of the chromosome on which the gene resides is considered a feature of polysomy. In Cases 19 and 22, the copy number of the sequence located on the long arm (7q21) of the same chromosome as the EGFR was not increased. Thus, this coamplification does not reflect the polysomy of chromosome 7. Instead, it may represent a large amplicon that includes 7p12 (locus of EGFR gene) and the chromosome 7 centromeric region. A recent comparative genomic hybridization (CGH) study of breast cancer samples showed that an amplicon including the HER-2 locus (17q11.2-q12) extended to $17 \mathrm{p},{ }^{35}$ while another CGH study reported that discontinuous 'zebra' patterns of allelic imbalance at $17 \mathrm{q}$ may be caused by gene amplification. ${ }^{36}$ In the present study, it was not clear whether the amplicons in coamplification-type gene amplification contains centromeric regions continuously or discontinuously, and if the latter is case, it is possible that other genes that play a role in colon cancer development and progression may be coamplified.

Breast cancers have attracted much attention because $20-30 \%$ of them exhibit HER-2 overexpression with gene amplification, ${ }^{37}$ and use of trastuzumab has increased the median survival time in metastatic breast cancer patients overexpressing HER-2 2. Cancers of head and neck, and nonsmall-cell lung cancers also exhibit a high frequency of EGFR overexpression ranging 34-62\% with and without gene amplification. ${ }^{38,39}$ Recent clinical studies reported that cetuximab or gefitinib showed some clinical benefit in patients of cancers of head and neck, and non-small-cell lung cancers. ${ }^{40}$ The present study demonstrated that HER-2 and EGFR abnormalities were found in only a minority of colorectal cancer cases. However, the small prevalences do not preclude patients of colorectal cancer from getting benefit from the receptor inhibitory therapies, because although small in number, high amplification/high overexpression of $H E R-2$ or EGFR appears to define a distinct genotype/phenotype of colorectal cancer with properties that could respond well to the new adjuvant therapies.

Since possible targets of these adjuvant chemotherapies are metastatic tumors, it is relevant to characterize any genetic heterogeneity between primary and metastatic tumors, and more importantly between different metastatic tumors. Our findings showed that cancer cells overexpressing HER-2 were found both in the primary and metastatic tumors, and therefore examination of primary tumors could reliably predict the HER-2 status of the metastatic foci. These results also suggest that HER2 could be a promising target for adjuvant therapy in colorectal cancers. In contrast, cancer cells with amplification and high-level overexpression of EGFR were a minor population in most primary tumors and displayed marked heterogeneity in metastatic sites, probably because of the instability of the amplified genes. This suggests that treatment that targets this molecule may encounter difficulties due to the emergence of resistant subclones lacking this alteration. It will be important to evaluate the gene and protein status of HER-2 and EGFR to design future adjuvant therapies for patients with colorectal cancers.

\section{Acknowledgements}

This work was supported by grants from The Japanese Ministry of Education, Sports, Science and Cultures Nos. C 1260157, C 14570161, and C 15590298. 


\section{References}

1 Yamamoto T, Ikawa S, Akiyama T, et al. Similarity of protein encoded by the human c-erb-B-2 gene to epidermal growth factor receptor. Nature 1986;319: 230-234.

2 Treish I, Schwartz R, Lindley C. Pharmacology and therapeutic use of trastuzumab in breast cancer. Am J Health Syst Pharm 2000;57:2063-2076.

3 Cohen MH, Williams GA, Sridhara R, et al. FDA drug approval summary: gefitinib (ZD1839) (Iressa) tablets. Oncologist 2003;8:303-306.

4 Takehana T, Kunitomo K, Kono K, et al. Status of cerbB-2 in gastric adenocarcinoma: a comparative study of immunohistochemistry, fluorescence in situ hybridization and enzyme-linked immuno-sorbent assay. Int J Cancer 2002;98:833-837.

5 Ooi A, Kobayashi M, Mai M, et al. Amplification of c-erbB-2 in gastric cancer: detection in formalin-fixed, paraffin-embedded tissue by fluorescence in situ hybridization. Lab Invest 1998;78:345-351.

6 Ishikawa T, Kobayashi M, Mai M, et al. Amplification of the c-erbB-2 (HER-2/neu) gene in gastric cancer cells. Detection by fluorescence in situ hybridization. Am J Pathol 1997;151:761-768.

7 Hirashima N, Takahashi W, Yoshii S, et al. Protein overexpression and gene amplification of c-erb B-2 in pulmonary carcinomas: a comparative immunohistochemical and fluorescence in situ hybridization study. Mod Pathol 2001;14:556-562.

8 Takehana T, Kunitomo K, Suzuki S, et al. Overexpression of epidermal growth factor receptor in gastric carcinomas is rare but occurs predominantly by gene amplification. Clin Gastroenterol Hepatol 2003;1:438-445.

9 Flemming ID, Cooper JS, Earl Henson D, et al (eds). Colon and rectum, In: AJCC Cancer Staging Manual, 5th edn. Lippincott Williams and Wilkins: Philadelphia, PA, 1977, pp 83-88.

10 Hamilton SR, Vogelstein B, Sobin LH, et al. Carcinomas of the colon and rectum, In: Hamilton SR, Aaltonen LA (eds). World Health Organization Classification of Tumours. IARC Press: Lyon, France, 2000, pp 105-119.

11 Kobayashi M, Ooi A, Oda Y, et al. Protein overexpression and gene amplification of c-erbB-2 in breast carcinomas: a comparative study of immunohistochemistry and fluorescence in situ hybridization of formalin-fixed, paraffin-embedded tissues. Hum Pathol 2002;33:21-28.

12 Kunitomo K, Takehana T, Inoue S, et al. Detection of c-erbB-2 (HER-2/neu) amplification in breast carcinoma by fluorescence in situ hybridization on tissue sections and imprinted cells. Pathol Int 2002;52:451-457.

13 Kitayama Y, Igarashi H, Sugimura H. Initial intermittent microwave irradiation for fluorescence in situ hybridization analysis in paraffin-embedded tissue sections of gastrointestinal neoplasia. Lab Invest 2000;80:779-781.

14 Thomson TA, Hayes MM, Spinelli JJ, et al. HER-2/neu in breast cancer: interobserver variability and performance of immunohistochemistry with 4 antibodies compared with fluorescent in situ hybridization. Mod Pathol 2001;14:1079-1086.

15 Landis JR, Koch GG. The measurement of observer agreement for categorical data. Biometrics 1977;33: 159-174.
16 Nathanson DR, Culliford ATT, Shia J, et al. HER 2/neu expression and gene amplification in colon cancer. Int J Cancer 2003;105:796-802.

17 Arnaout AH, Dawson PM, Soomro S, et al. HER2 (c-erbB-2) oncoprotein expression in colorectal adenocarcinoma: an immunohistological study using three different antibodies. J Clin Pathol 1992;45: 726-727.

18 Kay EW, Mulcahy H, Walsh CB, et al. Cytoplasmic C-erbB-2 protein expression correlates with survival in Dukes' B colorectal carcinoma. Histopathology 1994;25:455-461.

19 Caruso ML, Valentini AM. Immunohistochemical p53 overexpression correlated to c-erbB-2 and cathepsin D proteins in colorectal cancer. Anticancer Res 1996; 16:3813-3818.

20 D’Emilia J, Bulovas K, D’Ercole K, et al. Expression of the c-erbB-2 gene product (p185) at different stages of neoplastic progression in the colon. Oncogene 1989;4:1233-1239.

21 Nakae S, Shimada E, Urakawa T. Study of c-erbB-2 protein and epidermal growth factor receptor expression and DNA ploidy pattern in colorectal carcinoma. J Surg Oncol 1993;54:246-251.

22 Osako T, Miyahara M, Uchino S, et al. Immunohistochemical study of c-erbB-2 protein in colorectal cancer and the correlation with patient survival. Oncology 1998;55:548-555.

23 McKay JA, Loane JF, Ross VG, et al. c-erbB-2 is not a major factor in the development of colorectal cancer. Br J Cancer 2002;86:568-573.

24 Kapitanovic S, Radosevic S, Kapitanovic M, et al. The expression of p185(HER-2/neu) correlates with the stage of disease and survival in colorectal cancer. Gastroenterology 1997;112:1103-1113.

25 Slamon DJ, Godolphin W, Jones LA, et al. Studies of the HER-2/neu proto-oncogene in human breast and ovarian cancer. Science 1989;244: 707-712.

26 Lemoine NR, Jain S, Silvestre F, et al. Amplification and overexpression of the EGF receptor and c-erbB-2 proto-oncogenes in human stomach cancer. $\mathrm{Br} \mathrm{J}$ Cancer 1991;64:79-83.

27 Mayer A, Takimoto M, Fritz E, et al. The prognostic significance of proliferating cell nuclear antigen, epidermal growth factor receptor, and mdr gene expression in colorectal cancer. Cancer 1993; 71:2454-2460.

28 Goldstein NS, Armin M. Epidermal growth factor receptor immunohistochemical reactivity in patients with American Joint Committee on Cancer Stage IV colon adenocarcinoma: implications for a standardized scoring system. Cancer 2001;92: 1331-1346.

29 Nishikawa R, Ji XD, Harmon RC, et al. A mutant epidermal growth factor receptor common in human glioma confers enhanced tumorigenicity. Proc Natl Acad Sci USA 1994;91:7727-7731.

30 Radinsky R, Risin S, Fan D, et al. Level and function of epidermal growth factor receptor predict the metastatic potential of human colon carcinoma cells. Clin Cancer Res 1995;1:19-31.

31 Layfield LJ, Bernard PS, Goldstein NS. Color multiplex polymerase chain reaction for quantitative analysis of epidermal growth factor receptor genes in colorectal adenocarcinoma. J Surg Oncol 2003;83: 227-231. 
32 Fried M, Feo S, Heard E. The role of inverted duplication in the generation of gene amplification in mammalian cells. Biochim Biophys Acta 1991;1090: 143-155.

33 Dolf G, Meyn RE, Curley D, et al. Extrachromosomal amplification of the epidermal growth factor receptor gene in a human colon carcinoma cell line. Genes Chromosomes Cancer 1991;3:48-54.

34 Ruiz JC, Wahl GM. Chromosomal destabilization during gene amplification. Mol Cell Biol 1990; 10:3056-3066.

35 Isola J, Chu L, DeVries S, et al. Genetic alterations in ERBB2-amplified breast carcinomas. Clin Cancer Res 1999;5:4140-4145.

36 Barlund M, Tirkkonen M, Forozan F, et al. Increased copy number at $17 q 22-q 24$ by $\mathrm{CGH}$ in breast cancer is due to high-level amplification of two separate regions. Genes Chromosomes Cancer 1997;20:372-376.
37 Bergstein I. Molecular alterations in breast cancer, In: Bowcock AM (ed). Breast Cancer. Humana Press: Totowa, NJ, 1999, pp 143-170.

38 Grandis JR, Tweardy DJ, Melhem MF. Asynchronous modulation of transforming growth factor alpha and epidermal growth factor receptor protein expression in progression of premalignant lesions to head and neck squamous cell carcinoma. Clin Cancer Res 1998; 4:13-20.

39 Hirsch FR, Varella-Garcia M, Bunn Jr PA, et al. Epidermal growth factor receptor in non-small-cell lung carcinomas: correlation between gene copy number and protein expression and impact on prognosis. J Clin Oncol 2003;21:3798-3807.

40 Baselga J. New therapeutic agents targeting the epidermal growth factor receptor. J Clin Oncol 2000; 18:54S-59S. 